\title{
Flood Risk Assessment Based on Flood Hazard and Vulnerability Indexes
}

\author{
Constantin Buta, Geanina Mihai, Madalina Stănescu
}

\begin{abstract}
Within this paper, a methodology for assessing the flood risk was developed by extracting the essential factors that favor the generation of flood risk. These factors, that had a sufficient number of data for a proper comparative analysis, are: potentially affected population based on population density, total agricultural area, total built-up area and the historical maximum amount of precipitation recorded in $\mathbf{2 4}$ hours. The flood risk assessment is presented in the form of indices calculation for all these factors and maps generated which representing the results of the calculation of the above-mentioned factors and the results of the flood risk index calculation.

Urban floods have particularities that must be presented in detail to understand the flood phenomenon, which is why this paper takes into consideration these areas. In order to determine the probability of urban floods, all disturbing factors that may affect the urban area must be taken into account.

The method presented in this paper can be used in sectoral planning activities and integrated planning studies, and for damage assessment.
\end{abstract}

Keywords - flood hazard, flood vulnerability, flood risk assessment

\section{INTRODUCTION}

In 2007, with the European Flood Directive (EFD) [9], legislation came with the aim "to reduce the risk of adverse consequences from flooding, especially for human health and life; the environment; cultural heritage; economic activity; and infrastructure." The EFD has been implemented in the Romanian Legislation, also taking into account the applicable national legislation. Romanian Waters Administration fulfilled the requirements of the Flood Directive, as far as the following steps are concerned: (i) preliminary assessment, (ii) hazard and flood-risk maps, and (iii) management plans for flood risk.

Flooding is a natural hazard that means the temporarily covering with water of a teritory or land that is not normally covered with water [1]. Flooding is a result of heavy or continuous rainfall exceeding the absorptive capacity of soil and the flow capacity of rivers, streams, and coastal areas. This causes a watercourse to overflow its banks onto adjacent lands. Most rainfall records are based on a measured depth of water received over a fixed period of time.

Floods are usually described in terms of their statistical frequency. A "100-year flood" describes an event or an area subject to a $1 \%$ probability of a certain size flood occurring in any given year. This concept does not mean such a flood will occur only once in one hundred years. Whether or not it occurs in a given year has no bearing on the fact that there 


\section{sciendo}

is still a $1 \%$ chance of a similar occurrence in the following year. Since floodplains can be mapped, the boundary of the 100-year flood is commonly used in floodplain mitigation programs to identify areas where the risk of flooding is significant. Any other statistical frequency of a flood event may be chosen depending on the degree of risk that is selected for evaluation, e.g., 5-year, 20-year, 50-year, 500-year floodplain.

Romania has been severely affected by devastating floods in the last decade. In the years 2005, 2006, 2008, 2010, 2014, 2016 there were large-scale floods with catastrophic effects. Thus, this paper aimed to understand the flood hazard phenomenon into urban areas throughout Dobrogea Region (Romania), having as input data a number of ten localities whose hydrological, social and environmental data were entered and interpreted in order to make a zonal map of hazard, vulnerability and flood risk.

All cities studied are characterized by an area of influence. The cumulation between the city and its afferent area is called "station" in this work. The names of the stations used are exemplified below: Medgidia, Tulcea, Adamclisi, Sulina, Cernavoda, Jurilovca, Hârșova, Constanța, Corugea, and Mangalia.

Based on the synthesis reports on the consequences of the floods, the topographic maps and the orthophotographic interpretations and geographical information layers were created within the project, on the areas affected by floods at the level of the sectors described by the cities work station.

\subsection{General notions}

The concept of flood risk, in the EFD, "means the combination of the probability of a flood event and of the potential adverse consequences for human health, the environment, cultural heritage and economic activity associated with a flood event" [9].

This paper presents the current stage of flood hazard, identifying the parameters that determine the occurrence of floods, numerical materialization of parameters, identification and calculation of the impact of floods in the Dobrogea area (Romania), centralizing all data through a graphical representation.

\subsubsection{Flood hazard}

Flood hazard is one of the two main components of risk, being defined by the probability of exceeding the maximum rainfall.

According to the scientific papers and based on good practices, it is recommended to use 3 hazard classes, respectively 3 areas whose precipitation has a low, medium and high probability of exceeding.

Even if for the medium hazard class and, especially, for the low one, the average period of overcoming can be long, the magnitude of the events and consequences can be catastrophic [2].

Hazard maps indicate only the possibility of a dangerous hydrological phenomenon (exceeding the normal limits of precipitation or flooding areas, water depth, etc.) and can be used to develop socio-economic development plans. Moreover, the hazard maps completed by the flood risk maps are useful tools for the Romanian authorities (local, county, national) in order to elaborate the regional and local development plans, in order to take the necessary measures for limiting the damages caused by the floods and the cost-benefit analysis for the future development projects of the hydrotechnical works and not only.

Overall, flood hazard maps indicate a geographical area where normal rainfall values can be exceeded, thus favoring thefloods. 


\subsubsection{Flood vulnerability}

Vulnerability is the extent to which a system can be affected by impact with a hazard and includes all physical, social, economic and environmental conditions that increase the susceptibility of that system.

Identical to hazard, vulnerability is an indicator of a future state of a system, defining the degree of ability or inability of the system to cope with the expected stress.

In Romania, the lack of firm legislation at the beginning of the transition period led to a worsening of environmental conditions through uncontrolled deforestation, destruction of forest curtains and irrigation systems and an increase in the impact of natural hazards on society [6].

Vulnerability can be voluntary or involuntary. It depends on the infrastructure and socioeconomic conditions of a space; reducing exposure to hazard implicitly reduces vulnerability.

Based on these general considerations, the main effects of floods in our country will be highlighted below, namely on agriculture and forestry, on water supply of localities, on industry and transport, on health, effects that are reflected, ultimately, on the quality of life of the population.

\subsubsection{Flood effects}

Flood effects can be classified according to how they relate to the environment directly or indirectly. be made:

If we analyze the effect of floods in terms of damage, the following classifications can

- Effects on the population, as well as its movable and immovable property;

- Effects on social objectives;

- Effects on production capacities (companies, industrial platforms, power plants, agrozootechnical farms, fish farms, ports and others);

- Effects on dams and other hydrotechnical works representing sources of risk downstream,

- Effects on road, rail and naval communications

- Effects on power supply networks with: electricity, gas, water supply and sewerage sources and systems, treatment plants, telecommunication network.

- Effects on the natural environment (aquatic ecosystems, forests, agricultural lands, localities and urban environment).

Indirect economic damage consists of the effects that floods have on the temporary or permanent interruption of production processes, on delays in the delivery of products and even by reduced exports. Then come the additional transport costs, those of defense through the measures adopted during the floods, not to mention the expenses incurred for the normalization of the situation and the resumption of economic activities, as well as for the payment of insurance for material and human goods.

In addition to the quantifiable economic damage, floods also have effects that affect both social life and the environment through the ecological consequences they can produce.

The negative social effects consist primarily of the loss of human lives and their subsequent consequences on the lives of human communities and society in general.

The negative ecological effects are obvious by degrading the environment by affecting the quality of its factors. During floods, surface water pollution takes place by entraining in the riverbeds all the waste from the water banks, by the decomposition of drowned and transported animals, by the destruction of the transport pipes of petroleum products, etc. Groundwater pollution and even soil pollution in flooded areas are carried out if the waters carry such substances [4]. 


\section{sciendo}

130 Ovidius University Annals Series: Civil Engineering, Year 22, 2020

1.1.4. Flood prevention and treatment measures

At national level, Romania has initiated a catalog of measures to be taken regarding the hazardous aspect of floods.

The proposed measures aim at the five areas of action, in close connection with the flood risk management cycle [8]:

- Prevention;

- Protection;

- Preparedness;

- Awareness;

- Response and Recovery.

In order to limit the harmful effects of the hazard to floods, a series of actions and measures can be prepared that help to reduce the harmful effects:

- observation of past and present flood heights and flooded areas,

- statistical, hydrological and hydraulic analyzes,

- mapping of flooded areas and flood heights for future flood scenarios,

- long-term planning and regulation of land use,

- engineering design and building structures to control or withstand floods,

- medium-term monitoring, forecasting and emergency response planning;

- short-term monitoring, warning and response operations.

\section{METODOLOGY AND DATA ANALYSIS}

\subsection{Flood hazard index (FHI)}

In general hazard quantifies the probability of occurrence of a potentially damaging phenomenon. Since hazard represents a probability, it ranges between 0 and 1 . Here, it is measured as the product of magnitude and the associated frequency of occurrence of a flood event. Using a weighting system based on the cumulative distribution function (Figure 1), weight $(\mathrm{W})$ and rating $(\mathrm{R})$ scores are assigned based on the normal cumulative probability function to flood hazard assessment using severity and occurrence probability [3].

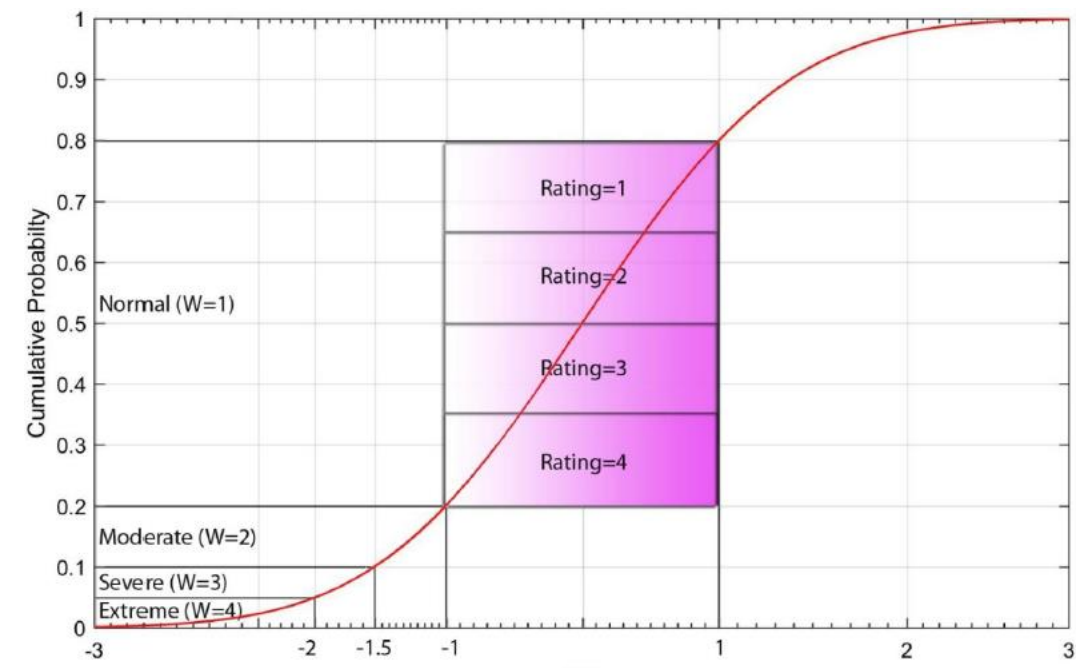

Fig. 1. Weight and rating scores based on normal cumulative probability distribution of FHI 
Weight scores are determined by considering the maximum amount of precipitation recorded in 24 hours for FHI intervals, such that [5]:

weight $=1$ for normal flood (NF),

weight $=2$ for moderate flood $(\mathrm{MF})$,

weight $=3$ for severe flood $(\mathrm{SF})$,

weight $=4$ for extreme flood $(\mathrm{EF})$.

Weights for FHI $<0$ are equal to zero. Similarly, rating scores are assigned from 1 to 4 in increasing order dividing the interval of cumulative probabilities in each flood range.

The weight and rating scores are assigned based on the intervals which are illustrated Figure 1. Multiplication of weight and rating scores generates Flood Hazard Score (FHS).

Then FHS is calculated for each FHI values. The aggregated FHS is obtained by using Equation 1 for 10 rain gauges:

$$
(F H S)_{i}=\sum_{i=1}^{N} W_{i} x R_{i}
$$

where: $\mathrm{N}$ refers to number of maximum amount of precipitation recorded in 24 hours values for selected time interval.

After obtaining FHSs for 10 gauges flood hazard index (FHI) contour map (Fig. 6) is generated by using Thiessen methodology. The Flood Hazard Index (FHI) was calculated for provinces, using contour map percentage area A (\%) and corresponding FHS are aggregated within province boundary by using Equation 2:

$$
(F H I)_{i}=\sum_{i=1}^{n} A(\%)_{i} x(F H S)_{i}
$$

\subsection{Flood Vulnerability Index (FVI)}

Vulnerability, as explained above, is a relative measure of the degree to which a system is susceptible to damage from an event.

Vulnerability is more associated with the socio-economic conditions of a region and is a potential indicator for measuring the maximum damage during the event.

Several studies have linked the assessment of vulnerability to the effects of climate change on water resources; however they may not adequately reflect flood scenarios, especially at local and sectoral level. Thus, the selection of vulnerability indices varies between sectors so that their choice will be directly related to local studies and to chance in particular.

For the calculation of the Flood Vulnerability Index (FVI) in this study 4 socioeconomic indices were chosen which include: The maximum historical amount of precipitation in 24 hours (P), Total Agricultural Lands (TAL), Population Density (PD) and the Total Built Area (TBA) of each city (station) as follows:

$$
F V I=\left(P_{n}+T A L_{n}+P D_{n}+T B A_{n}\right) / 4
$$

Where the indices below represent normalized values in relation to:

- Pn - The maximum historical amount of precipitation in 24 hours

- TALn - Total Agricultural Lands

- PDn - Population Density

- TBA $n$ - Total Built Area 


\section{sciendo}

Each indicator is normalized by its own level and a common distribution interval will be established for all indicators so as to prevent different unit effects.

Then FVI is reclassified into 4 classes as in table 1:

Table 1 Flood Vulnerability Index (FVI) classification

\begin{tabular}{|c|c|c|}
\hline No.crt. & Vulnerability classes & Distribution interval \\
\hline 1 & Low & $0<\mathrm{FVI}<0.25$ \\
\hline 2 & Moderate & $0.25<\mathrm{FVI}<0.5$ \\
\hline 3 & High & $0.5<\mathrm{FVI}<0.75$ \\
\hline 4 & Very high & $0.75<$ FVI $<1$ \\
\hline
\end{tabular}

\subsection{Flood Risk Index (FRI)}

Flood risk assessment has been studied by integrating hazard and vulnerability assessments. Thus, the Flood Risk Index (FRI) was calculated by multiplying the Flood Hazard Index (FHI) with the Flood Vulnerability Index (FVI).

There will be no risk when either FVI or FHI will be equal to 0 and a higher value of FVI or FHI will result in an increased risk from the flood event.

Therefore, it is very important to quantify both the risk of flood hazard (FHI) and the risk of flood vulnerability (FVI).

Quantitative flood risk assessments are vital to deal with the consequences of flood risk; therefore the Flood Risk Index (FRI) is calculated using a conceptual model presented in the figure below using the Flood Hazard Index (FHI) and the Flood Vulnerability Index (FVI).

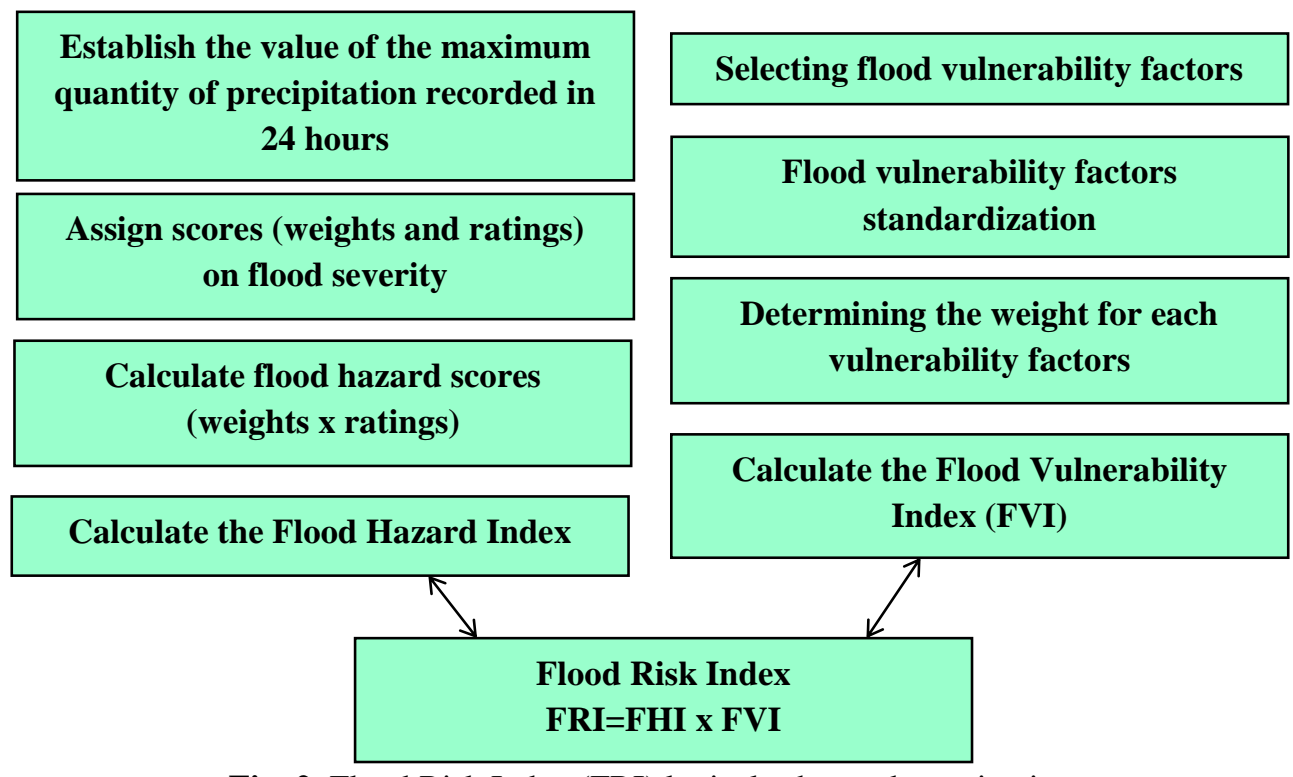

Fig. 2. Flood Risk Index (FRI) logical scheme determination 


\section{RESULTS AND DISCUSSIONS}

\subsection{Flood Hazard Assessment}

To obtain the Flood Hazard Index (FHI), the A\% contour areas on the map with the corresponding Flood Hazard Score (FHS), are comprised between the borders of the Dobrogea area using Equation (2).

It is established that the Flood Hazard Score (FHS) is represented by the Value of the Maximum Amount of Historical Precipitation per $24 \mathrm{~h}$, then it is calculated with equation (1) (for example FHS calculated for Constanța is equal to $0,061 \times 1=0,061$ ).

The same procedure is performed for each of the 10 stations of Dobrogea, then the values of the Flood Hazard Indices(FHI) are normalized by their reclassification between 0 and 1 .

We obtained the normalization of the indicators using the method proposed by the United Nations Development Program (UNDP) using the following formula [7]:

$$
\mathrm{X}=\left(\mathrm{X}_{\max }-\mathrm{X}_{\mathrm{i}}\right) / \mathrm{X}_{\max }-\mathrm{X}_{\min }
$$

In both equations, $\mathrm{Xi}$ is the normalized value of the variable $\mathrm{xi}$, and $\mathrm{xmin}$ are the minimum and xmax are the maximum values of the data set.

All stations chosen in the Dobrogea area are classified based on the Flood Hazard Index (FHI) into four classes of values, such as "low" between 0 and 0.25 , "moderate" between 0.25 and 0.50 , "high" between 0.5 and 0.75 , "very high" between 0.75 and 1 .

The map for these indices will be generated as shown in Figure 3 below:

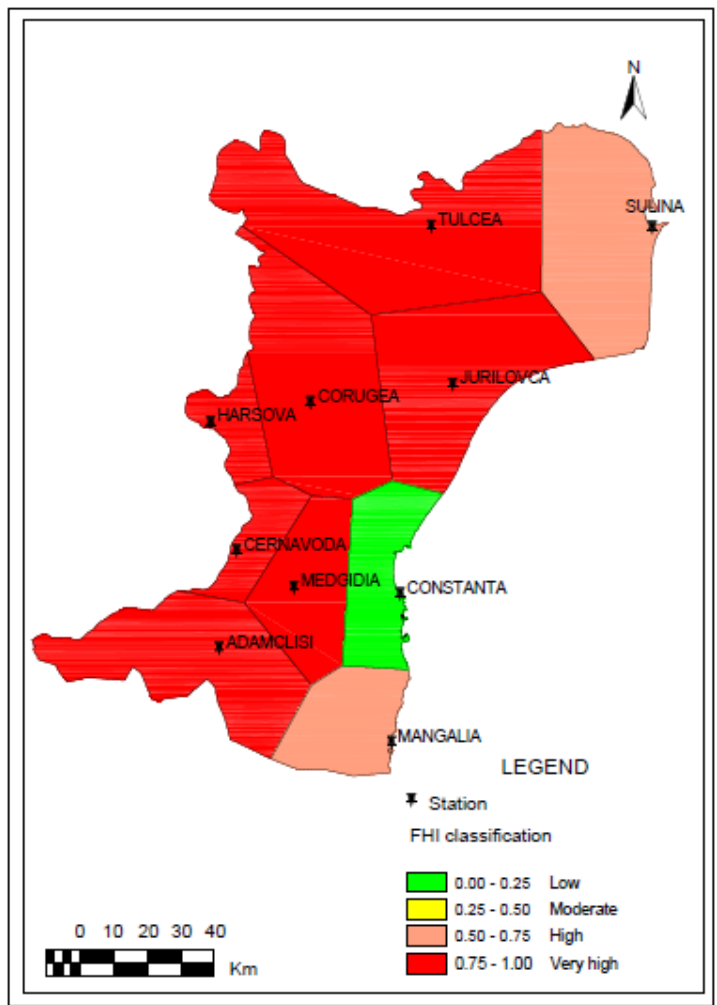

Fig. 3. Flood Hazard Index Map 


\section{sciendo}

134 Ovidius University Annals Series: Civil Engineering, Year 22, 2020

\subsection{Flood Vulnerability Assessment}

In general, in order to cope with the consequences of natural disasters, vulnerability is considered as an indicator of sensitivity or resilience.

Several studies have investigated the link between the impact of climate change on water resources and vulnerability to floods, and yet the objective assessment of vulnerability often neglects socio-economic variables.

Therefore, in order to fill these gaps in the evaluation, we introduced in the equation of the Flood Vulnerability Index (FVI), some local socio-economic variables such as (population density or cities water supply).

In this paper, depending on the availability of socio-economic data, four indicators were used, these being - The maximum historical amount of precipitation in 24 hours $(\mathrm{P})$, total agricultural land (TAL), population density (PD) and total built area (TBA).

The calculation of the flood vulnerability is performed in the first phase using the four socio-economic indicators as presented in equation (3), then the vulnerability map is generated based on the Flood Vulnerability Index (FVI) as in Figure 4.

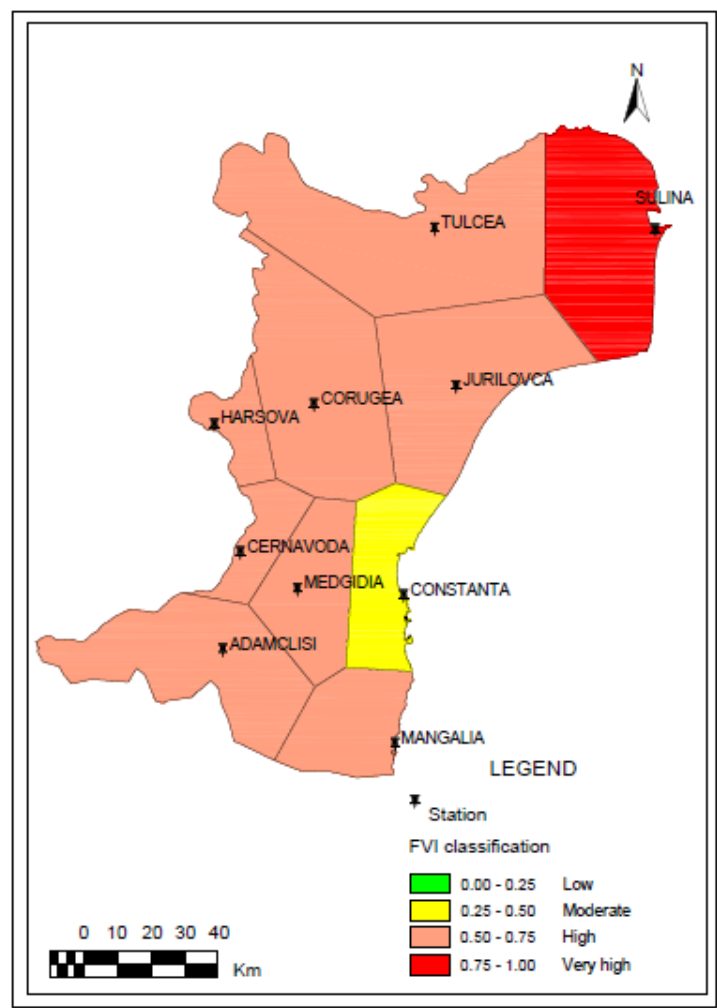

Fig. 4. Flood Vulnerability Index Map

It will be noted that in the case of the 10 stations in Dobrogea there is no low vulnerability class, there is only one station of moderate vulnerability - Constanța and we can say that most stations are in high vulnerability classes (Medgidia, Adamclisi, Cernavoda, Harsova, Corugea, Tulcea, Jurilovca and Mangalia) and one very high vulnerability class (Sulina). 


\subsection{Flood Risk Assesment}

In this paper, the Flood Risk Index (FRI) is based on meteorological and socioeconomic information by multiplying the Flood Hazard Index (FHI) with the Flood Vulnerability Index (FVI) and the flood risk map is generated based on the Flood Risk Index. Flood Risk Index (FRI) is shown in Figure 5.

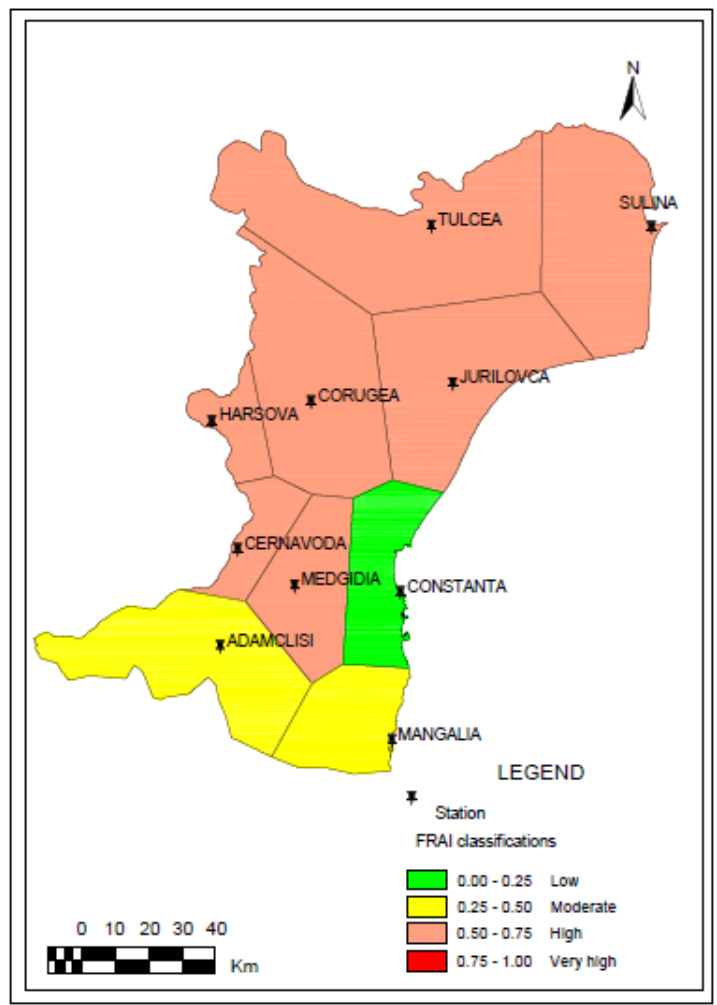

Fig. 5. Flood Risk Index (FRI)

Each region is classified into four groups similar to the intervals in the Flood Hazard Index (FHI) class and Flood Vulnerability Index (FVI) class.

If one of the FVI or FHI is equal to "0", the FRI score becomes "0", which means that there is no risk of flooding, as for example in Constanța where we have no risk of flooding as seen in Figure 4. Similarly, if one of the Indices (Flood Vulnerability or Flood Hazard) is higher, then the Flood Risk Assessment Index becomes higher, so we can say that the two indices have important contributions to flood risk assessment.

This method of flood risk assessment can identify and compare the risk of flooding between local stations in a region and to mitigate and reduce the negative impact of the flood hazard.

The maps generated for flood risk, vulnerability and risk for all 10 stations located in Dobrogea Region, will contribute to the identification of the spatial distribution of flood risk indicators.

The map for FHI shows us that 7 stations are in a very high state of risk (where we have the "very high" class,) the rest being with a high, moderate and even non-existent 


\section{sciendo}

136 Ovidius University Annals Series: Civil Engineering, Year 22, 2020

impact. Thus, based on the Flood Hazard Indices (FHI) map, Constanța station does not present any flood hazard. The most predominant class is very high which it is presented for Medgidia, Adamclisi, Cernavoda, Hârşova, Corugea, Tulcea and Jurilovca stations. Based on the Flood Hazards Vulnerability map there are no stations classified at low level of flood vulnerability and only one station is classified as moderate flood vulnerability. Here the most stations are occupied by classes with high food vulnerability.

To identify and illustrate the flood risk for all 10 stations uniform spread in Dobrogea Region, we centralized the results for the Flood Hazard Index (FHI), the Flood Vulnerability Index (FVI) and we calculated the Flood Risk Index (FRI) in Table 2.

Table 2 Values of FHI, FVI and FRI indices for the 10 cities (stations)

\begin{tabular}{|c|c|c|c|c|c|c|c|}
\hline $\begin{array}{c}\text { No. } \\
\text { crt. }\end{array}$ & Station & \multicolumn{2}{|c|}{$\begin{array}{c}\text { Flood Hazard Index } \\
\text { FHI }\end{array}$} & $\begin{array}{c}\text { Flood Vulnerability } \\
\text { Index } \\
\text { FVI }\end{array}$ & \multicolumn{2}{c|}{$\begin{array}{c}\text { Flood Risk Index } \\
\text { FRI }\end{array}$} \\
\hline 1 & Medgidia & 0.93 & Very high & 0.57 & High & 0.54 & High \\
\hline 2 & Adamclisi & 0.94 & Very high & 0.50 & High & 0.47 & Moderate \\
\hline 3 & Cernavodă & 0.99 & Very high & 0.65 & High & 0.65 & High \\
\hline 4 & Harșova & 0.93 & Very high & 0.61 & High & 0.57 & High \\
\hline 5 & Corugea & 0.96 & Very high & 0.63 & High & 0.60 & High \\
\hline 6 & Tulcea & 1.00 & Very high & 0.59 & High & 0.59 & High \\
\hline 7 & Sulina & 0.67 & High & 0.78 & Very high & 0.52 & High \\
\hline 8 & Jurilovca & 0.98 & Very high & 0.64 & High & 0.62 & High \\
\hline 9 & Constanța & 0.00 & Low risk & 0.41 & High & 0.00 & Low risk \\
\hline 10 & Mangalia & 0.63 & High & 0.68 & High & 0.43 & Moderate \\
\hline
\end{tabular}

From the resulting table we can see that there is low risk on Constanța station and high and very high risk classes are missing.

Thus, it is observed that we have the predominant high risk class (7 stations Medgidia, Cernavoda, Hârșova, Corugea, Tulcea, Sulina and Jurilovca) and the moderate risk class (Adamclisi and Mangalia) which means that the Dobrogea area due to its settlement that includes Delta The Danube and the Black Sea can be classified as a high risk area depending on the geographical position of the stations, namely surrounded mainly by water.

\section{CONCLUSIONS}

In this paper, the risk of floods is achieved by incorporating hazard and vulnerabilities for cities located in Dobrogea Region.

The analysis of the flood vulnerability index is found using four indicators in relation to water demand and need.

Then the flood risk is obtained using the flood hazard index and the flood vulnerability index for the administrative sectors of Dobrogea.

For the study of the zonal variation of the floods, the flood hazard and vulnerability map and the risk map are generated.

It was thus observed that there was no risk on Constanța station and the very high risk class is missing and also that there is moderate risk for two stations, Adamclisi and Mangalia. Thus, it is observed that we have the high risk class on most stations (Medgidia, Cernavoda, Hârşova, Corugea, Tulcea, Sulina and Jurilovca). 
Moreover, we can say that the conceptual model of flood risk, which depends on socio-economic variables, helps to minimize the impact of floods in the Dobrogea area.

In general, this information helps us to identify the cities with the greatest vulnerability to floods but also to make a comparison between local areas (cities at flood risk).

These socio-economic indicators can also be used to make flood risk maps for scenario analysis and to develop strategies to minimize the flood impact.

\section{REFERENCES}

[1] Bălteanu D., Costache Andra (2006), Conceptul de vulnerabilitate. Aplicaţii în geografie, Revista Geografică, XII, Institutul de Geografie, Academia Română, Bucureşti [2] Connelly, Brian A et. all (1999)."Advanced Hydrologic Prediction System", Journal of Geophysical Research

[3] Dabanli Ismail, (2018), Drought Risk Assessment by Using Drought Hazard and Vulnerability Indexes, Nat. Hazards Earth Syst. Sci. Discuss., https://doi.org/10.5194/nhess2018-129

[4] Powell, W. Gabe, (2009), Identifying Land Use/Land Cover (LULC) Using National Agriculture Imagery Program (NAIP) Data as a Hydrologic Model Input for Local Flood Plain Management, Applied Research Project, http://ecommons.txstate.edu/arp/296/ Texas State University-San Marcos

[5] Rajsekhar, D., V. P. Singh, and A. K. Mishra (2015), Integrated drought causality, hazard, and vulnerability assessment 20 for future socioeconomic scenarios: An information theory perspective. J. Geophys. Res. Atmos., 120, 6346-6378 http://doi.org/10.1002/2014JD022670

[6] Săgeată Radu, Dumitrescu Bianca, et. all „Tipologii privind vulnerabilitatea la inundatii a oraselor din Romania” Institutul de Geografie, Academia Română

[7] UNDP, United Nation Development Program, (2004), Reducing Disaster Risk: a Challenge for Development. John S. Swift Co, New York

[8] Planul de Management al Riscului la Inundatii - Sinteza Nationala - 2016 http://www.mmediu.ro/app/webroot/uploads/files/2016-04-26_PMRI_Sinteza_Nationala.pdf [9] European Commission, Directive 2007/60/EC of the European Parliament and of the Council of 23 October 2007 on the assessment and management of flood risks. 2007. http://ec.europa.eu/environment/water/flood_risk/index.html

\section{Note:}

Constantin Buta - Ovidius University of Constanta, Bd. Mamaia nr. 124, 900356-Constanta, Romania (e-mail: buta.constantin @univ-ovidius.ro)

Geanina Mihai - Ovidius University of Constanta, Bd. Mamaia nr. 124, 900356-Constanta, Romania (e-mail: mihai.geanina@univ-ovidius.ro)

Mădălina Stănescu - Ovidius University of Constanta, Bd. Mamaia nr. 124, 900356-Constanta, Romania (e-mail: stanescu.madalina@univ-ovidius.ro) 